$\checkmark$ Research Square

\title{
Women's satisfaction and its' associated factors on institutional delivery services provided by public health facilities of Tanahun district, Nepal
}

Amritraj Pokhrel ( $\sim$ ashwinkancha1@gmail.com )

Gandaki Technical Training Center

Dipendra Yadav

Pokhara University

Prabin Sharma

Pokhara University

Research article

Keywords: Women's satisfaction, Institutional delivery services, Tanahun district

Posted Date: July 16th, 2020

DOI: https://doi.org/10.21203/rs.3.rs-41847/v1

License: (c) (i) This work is licensed under a Creative Commons Attribution 4.0 International License.

Read Full License 


\section{Abstract}

Background Institutional delivery is one of the important strategies to reduce the maternal related risk at the time of delivery. Satisfaction of women on labor and delivery care services has good influence on their health and results in subsequent utilization of health services. This study was focused to assess women's satisfaction and its' associated factors with institution delivery services in public health institutions.

Methods Cross- sectional study was conducted among 169 participants from June 2018 to November 2018 among women (having under one year children) residing in Tanahun district. Simple random sampling, face to face interview and semi structured interview schedule was used for the collection of data. Data were entered in Epi-Data and analyzed by SPSS. Ethical approval was obtained from Institutional Review Committee at Pokhara University and maintained during the process of research.

Results The age of the participants were between 16 to 40 years with median age 25 years (IQR = 7 Years). Most (93.5\%) of the participants were Hindu. Majority of the participants (57.4\%) and their husbands $(60.4 \%)$ had secondary level education. Almost all pregnancies $(99.4 \%)$ are planned and normal delivery was most common (77.5\%). The study shows that $55 \%$ of the women performed delivery in public health facilities. The study states high satisfaction score in health status of women after delivery (4.8) and lowest in availability of visitor's bed (2.99). Women's satisfaction and religion was seen to be significantly associated.

Conclusion Majority of the participants were satisfied with the services provided by public health facilities. Although, number of birthing centers were increasing, facilities in the health institution is not sufficient as required. Different factors such as cleanliness of delivery room, availability of staffs, medicine, visitor's bed and behavior of staff are some issues to be improved.

\section{Background}

Satisfaction is stated as a pleasant feeling that you get when women receive facilities they wanted, or when they have done something they wanted to do. ${ }^{[1]}$ Satisfaction of women is a subjective and dynamic perception of the extent to which health care facility you expect to receive. It is not important whether the women are right or wrong, but what is important is how the women feel. ${ }^{[2,3]}$ Satisfaction among pregnant women who were attending in health institution delivery is important measures to measure the quality of health care. The World Health Organization (WHO) emphasizes ensuring patient satisfaction as a means of secondary prevention of maternal mortality since satisfied women may be more likely to adhere to health providers' recommendations. ${ }^{[4]}$

Satisfaction on maternity care is a multidimensional construct embracing satisfaction with self and with the physical environment of delivery room and quality of care ${ }^{[5]}$. Quality of care is an important but often neglected issue in safe motherhood programs. Quality of care can be considered from the provider or 
user's perspective, and is differentiated into observed and perceived quality. Lack of quality health services results in the negligence on health services. The mother's assessment of quality is central because emotional, cultural and respectful supports are needed during labor and the delivery process. ${ }^{[6]}$ Women's satisfaction is one of the most frequently reported outcome measures of quality of care ${ }^{[3]}$ Satisfaction of women on labor and delivery care services has good influence on her health and results in subsequent utilization of health services. Thus knowledge about women satisfaction on labor and delivery care can increase the utilization of services. ${ }^{[7]}$

Several barriers are seen for the utilizing of institutional delivery services. The major factors are sociodemographic factors, maternal health factors, household factors and service related factors. ${ }^{\left[{ }^{8-11]}\right.}$ Some studies states that strategies like user-fee exemption for delivery and associated to enhance access, barriers still exist as universal coverage remains elusive. In some studies household headship, education, maternal age, and socioeconomic status were also significantly associated with place of delivery. ${ }^{[12]}$ Major three types of delay are seen for receiving institutional delivery services. They are delay in seeking care, delay in reaching care and delay in receiving care. Poor birth preparedness, knowledge on institution delivery, family influence on decision, geographical inaccessibility, and unmet needs of care in CEONC and fear of hospital setting ${ }^{[13]}$ are common factors related to first delay. Late and poor-quality referral, transport not available and inadequate decisions by husband/relatives have been associated with the second type of delay. Lack of supplies and staff, poor quality of care and multiple delays due to second referrals have been reported in the literature as part of the third type of delay. ${ }^{[14-16]}$

Many of the women get suffer from the maternal related health issue during pregnancy and childbirth. In 2015 , about $3,03,000$ women died due to maternal related cause. Among them $99 \%$ of the death are occurred in low and middle and low income country. More than $90 \%$ of all births benefitted from the presence of a trained midwife, doctor or nurse in middle and high income countries but, only less than half of all births in several low-income and lower-middle-income countries were assisted by such skilled health personnel. ${ }^{[17]}$ The South East Asia Region alone accounts for approximately one-third of the global maternal and child deaths annually. ${ }^{[18]} \mathrm{Nepal}$ government has introduced institutional delivery services as demand sided intervention. There has been increased in number of birthing center in the different district of the country. Nepal has committed to achieve $70 \%$ of all deliveries at institution by 2020 for achieving SDG target in 2030. Institutional delivery has been increased in all region expect state number two. ${ }^{[19]}$

Maternal morbidity and mortality highly decreases by safe delivery and skilled birth attendant at every birth. Improving maternal health and decreasing maternal mortality is the strategies for increasing emphasis on women's satisfaction with care in order to improve women's adherence to the service. ${ }^{[7]}$ Women's satisfaction is an element representative of quality of care. Therefore the most powerful prediction for measuring women's satisfaction on governmental health services was provider's behavior towards the patients, particularly respect and politeness. ${ }^{[20]}$ Maternal morbidity and mortality is highly decreased by safe delivery and skilled birth attendant at every birth which indicates women satisfaction with the services was the major factor for improving maternal health. One on the three strategies for 
reducing maternal mortality is taken as a maternal satisfaction. ${ }^{[7]} \mathrm{A}$ satisfied women will recommend center's services expressing their satisfaction to four or five peoples, while a dissatisfied women on the other hand will complain to twenty or more. ${ }^{[21]}$

Different factors are associated with the satisfaction of mother at institution delivery services. ${ }^{[22]}$ It is also essential to identify the factors involved in dissatisfaction, if a good health care system is sought. ${ }^{[21]}$ Most of the women were satisfied with receiving health care facility, providers skill, politeness of the staff waiting involvement in decision making, cleanliness and information received by them. ${ }^{[22]}$ More waiting

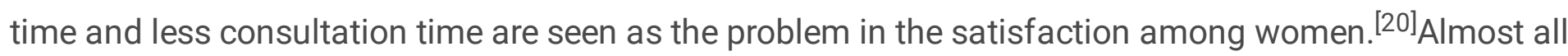
the study related to maternal satisfaction were based on hospital that have create a fear to women to tell about bad side of the services. ${ }^{[23]}$

Patient satisfaction has been increasing as the important outcome for health care delivery and increasing studies in the developing countries. Most studies are focused on low and middle income countries. Among them Nepal is one of the developing countries which has low institution delivery rate. So it becomes an important issue in the public health. Mainly women are not satisfied on health related services. Since Nepal is mountainous country, topographical variation can be seen as the barriers for receiving health services. Most of the people have low income. So government has provided these services free of cost. Instead of free institution delivery services the status of the institutional delivery is very low in the district. The study also attempts to describe the socio economic condition and its impact on institutional delivery services. The study mainly aims to find out the level of satisfaction among women who have taken institutional delivery services. There may be number of researches in this issue. So, it would be relevant to explore the women's satisfaction and its' associated factors at institution delivery services provided by public health institutions of Tanahun district.

\section{Methods}

Community based cross- sectional analytical study was conducted among 169 participants from June 2018 to November 2018 among women (having under one children) residing in Tanahun district which is located in Gandaki Province of Nepal. Simple random sampling technique was used. Face to face interview was the data collection technique. Semi structured interview schedule was used as a tool for assessing satisfaction on institutional delivery services. Pre-testing was conducted and necessary modification was made in questionnaire. Data were entered in Epic-Data (Version 3.1) and analyzed by SPSS 20.The data was analyzed in terms of frequency (percentage), mean (S.D) or median(IQR) as per necessary. Info- graphics was created and interpreted as per the need. Ethical approval was obtained from Institutional Review Committee, Pokhara University. Participants who involved in this research were provided with the information in relation to the topic.

\section{Results}




\section{Demographic Characteristics of Participants}

Majority $71.6 \%$ (121) were age between $20-29$ years. The median age of the participant was 25 years (IQR=7 years). Similarly majority of the participants follow Hinduism (93.5\%) and lived in joint family (60.9\%). Most of them $57.4 \%$ had secondary level education and only $3.6 \%$ were illiterate. Most of the women, $85.2 \%$ were housewife while remaining $14.8 \%$ (25) had some kind of work such as business job and daily wages.

\section{Reproductive Health related Characteristics of Participants}

Majority of the women, $62.1 \%$ were above 20 years. Similarly, most of the women, $62.7 \%$ were between 20 26 years during first pregnancy. Most of the participants (56.83\%) were primiparous while remaining $43.16 \%$. Among primiparous, most of them $67.1 \%$ had less than 14 hours labor time while $32.9 \%$. In case of multiparous $63.3 \%$ noticed less than 8 hours labor. Regarding the decision on service delivery point mostly husband $50.3 \%$ followed by wife/self (45.6\%) were involved.

Table 1 Demographic characters of the participants. 


\begin{tabular}{|c|c|c|}
\hline Characteristics $(\mathrm{n}=169)$ & Frequency(f) & Percentage (\%) \\
\hline \multicolumn{3}{|l|}{ Age } \\
\hline$<20$ & 12 & 7.1 \\
\hline $20-29$ & 121 & 71.6 \\
\hline$\geq 30$ & 36 & 21.3 \\
\hline \multicolumn{3}{|c|}{ Median age $=25$ years $(\mathrm{IQR}=7$ years), Minimum $=16$ years, Maximum $=40$ years } \\
\hline \multicolumn{3}{|c|}{ Religion } \\
\hline Hindu & 158 & 93.5 \\
\hline Buddhist & 6 & 3.6 \\
\hline Christian & 3 & 1.8 \\
\hline Muslim & 2 & 1.2 \\
\hline \multicolumn{3}{|l|}{ Family type } \\
\hline Joint & 103 & 60.9 \\
\hline Nuclear & 63 & 37.3 \\
\hline Extended & 3 & 1.8 \\
\hline \multicolumn{3}{|l|}{ Women's education } \\
\hline Graduate and above & 2 & 1.2 \\
\hline Under graduate & 16 & 9.5 \\
\hline Secondary & 97 & 57.4 \\
\hline Basic & 48 & 28.4 \\
\hline Illiterate & 6 & 3.6 \\
\hline \multicolumn{3}{|l|}{ Women's occupation } \\
\hline Housewife & 144 & 85.2 \\
\hline Business & 9 & 5.3 \\
\hline Agriculture & 7 & 4.1 \\
\hline Job & 6 & 3.6 \\
\hline Daily wages & 2 & 1.2 \\
\hline Others & 1 & .6 \\
\hline
\end{tabular}

Table 2: Reproductive health characteristics of participants 
Characteristics

Age of marriage $(n=169)$

$<20$ years

64

105

$\geq 20$ years

Median age $=20$ years (IQR $=4$ years), Minimum $=7$ years, Maximum=32years

Age of first pregnancy $(n=169)$

\begin{tabular}{lll}
$<20$ years & 45 & 26.6 \\
\hline $20-26$ years & 106 & 62.7 \\
$\geq 26$ years & 18 & 10.7
\end{tabular}

Median age $=21$ years $(\mathrm{IQR}=5$ years $)$, Minimum=16years, Maximum=32 years

Duration of labor (hours) for Primiparous $(n=79)$

$\begin{array}{lll}<14 \text { hours (Normal) } & 53 & 67.1 \\ \geq 14 \text { hours (Abnormal) } & 26 & 32.9\end{array}$

Duration of labor (hours) for Multiparous $(n=60)$

$<8$ hours (Normal) $\quad 38 \quad 63.3$

$\begin{array}{lll}\geq 8 \text { hours (Abnormal) } & 22 & 36.7\end{array}$

*Decision on Service Delivery Point

\begin{tabular}{lll} 
Husband & 85 & 50.3 \\
\hline Self & 77 & 45.6 \\
\hline Mother in law & 38 & 22.5 \\
\hline Father in law & 26 & 15.4 \\
\hline Sister in law & 2 & 1.2 \\
\hline Brother & 2 & 1.2 \\
\hline Sister & 3 & 1.8 \\
\hline Friends & 1 & 0.6 \\
\hline
\end{tabular}

Table 3 Health service related characteristics of participants 


\begin{tabular}{|c|c|c|}
\hline Characteristics & Frequency (n) & Percentage (\%) \\
\hline \multicolumn{3}{|l|}{ Mode of delivery } \\
\hline Normal vaginal delivery & 131 & 77.5 \\
\hline Caesarean section & 37 & 21.9 \\
\hline Normal delivery with episiotomy & 1 & .6 \\
\hline \multicolumn{3}{|c|}{ Duration of stay at health facility for Normal delivery (days) $(n=169)$} \\
\hline Less than two days & 106 & 62.7 \\
\hline Three or more days & 63 & 37.3 \\
\hline \multicolumn{3}{|c|}{ Median= $2(\mathrm{IQR}=4)$, Minimum= 1 day, Maximum= 9 days } \\
\hline \multicolumn{3}{|c|}{ Distance of health facility(hours) $(n=169)$} \\
\hline$<1$ hours & 113 & 66.9 \\
\hline 2-3 hours & 54 & 32.0 \\
\hline$>3$ hours & 2 & 1.2 \\
\hline \multicolumn{3}{|c|}{ Median= 1 hour $(\mathrm{IQR}=1)$, Minimum= 1 hours, Maximum= 4 hours } \\
\hline \multicolumn{3}{|l|}{ Available of incentives } \\
\hline Yes & 152 & 89.9 \\
\hline No & 17 & 10.1 \\
\hline
\end{tabular}

\section{Health Services Related Characteristics of Participants}

In case of delivery, more than three -fourth respondents $77.5 \%$ (131) had normal vaginal delivery. Nearly, two third of participant $62.7 \%$ (106) stayed in hospital for less than two days. The median stay in hospital was 2 days. Similarly two-third of the participant $66.9 \%$ (113) participant had to travel less than one hour to reach the hospital. Nearly, nine-tenth (89.9\%) had received the incentive provided by Nepal government. The amount of incentive was found to be different among women due to budgetary policy of every fiscal year. Median cost of the health services of respondents was NRs 13000 with IQR NRs21500, minimum NRs 100 and Maximum NRs 100000.

\section{Proportion of clients' satisfied}

There were twenty four items to measure the opinion of the respondents. The lowest score (2.99) was obtained for availability of visitors bed and highest score (4.80) was obtained by condition of women 
after delivery. Most of the variables value was more than four but food services (3.91) was followed by the lowest value. 4.2 to 4.8 range score was obtained to the services provided by staff in public health centers. Infrastructure of the health institution obtained the value range from 4.1 to 4.6 . Similarly, accessibility of the services had the score range value from .4.0 to 4.6.

\section{Satisfaction on institution delivery services}

According to the data obtained 55\% (93) respondents were satisfied with institutional delivery services while $45 \%$ (76) respondents were not satisfied. Almost all the participant $99.4 \%$ (168) wanted to visit to hospital for next delivery and suggested others for institute delivery.

Association of socio-demographic factors with clients' satisfaction during delivery period

Table 4: Association of socio-demographic factor with women's satisfaction. 


\section{Satisfaction Dissatisfaction}

93(55\%) 76(45\%)

\section{Age}

$<25$

$42(63.6 \%)$

24(36.4\%)

66

$x^{2}=3.432$

0.082

$25+$

$51(49.5 \%)$

$52(50.5 \%)$

103

Religion

Hindu

83(52.5\%) 75(47.5\%)

158

$\chi^{2}=6.084^{*}$

$0.024^{\star *}$

Non-Hindu

$10(90.9 \%) \quad 1(9.1 \%)$

11

Caste/Ethnicity

Upper Caste

$38(59.4 \%) \quad 26(40.6 \%)$

64

$\chi^{2}=1.180$

0.554

Janajati

$40(50.6 \%)$

$39(49.4 \%)$

79

Dalit and others

$15(57.7 \%)$

$11(42.3 \%)$

26

Family type

Single

Non-single

Women's education

Below basic

Secondary and above

$39(61.9 \%) \quad 24(38.1 \%)$

$54(50.9 \%)$

$52(49.1 \%)$

$63 \quad \chi^{2}=0.166$

0.201

106

Husbands Education

\begin{tabular}{|c|c|c|c|c|c|}
\hline Below basic & $34\{63 \%)$ & $20(37 \%)$ & 54 & \multirow[t]{2}{*}{$\chi^{2}=0.155$} & \multirow[t]{2}{*}{0.104} \\
\hline Secondary and above & $59(51.3 \%)$ & $56(48.7 \%)$ & 115 & & \\
\hline \multicolumn{6}{|l|}{ Women's Occupation } \\
\hline Unemployed & $81(56.2 \%)$ & $63(43.8 \%)$ & 144 & \multirow{2}{*}{$\chi^{2}=0.586$} & \multirow[t]{2}{*}{0.516} \\
\hline Employed & $12(48 \%)$ & $13(52 \%)$ & 25 & & \\
\hline \multicolumn{6}{|l|}{ Husband's Occupation } \\
\hline Unemployed & $9(64.3 \%)$ & $5(37.5 \%)$ & 14 & \multirow[t]{2}{*}{$\chi^{2}=0.528$} & \multirow[t]{2}{*}{0.580} \\
\hline Employed & $84(54.2 \%)$ & $71(45.8 \%)$ & 155 & & \\
\hline
\end{tabular}

*Fisher Exact test, **p value significant at $<0.05$, 
Table 4 represents the association between the socio-demographic variable and women's satisfaction in institution delivery services. Religion $\left(\chi^{2}=6.084, d f=1, p=0.0024\right)$ was significantly associated with women's satisfaction.

Association of Reproductive Health related Characteristics with Client satisfaction during delivery period Table 5: Association of reproductive health related characteristics with women's satisfaction

\begin{tabular}{|c|c|c|c|c|c|}
\hline \multirow[t]{3}{*}{ Variables } & \multicolumn{2}{|c|}{ Women's satisfaction } & \multirow[t]{3}{*}{ Total } & \multirow[t]{3}{*}{ Chi-square } & \multirow[t]{3}{*}{ p-value } \\
\hline & Satisfaction & Dissatisfaction & & & \\
\hline & $93(55 \%)$ & $76(45 \%)$ & & & \\
\hline \multicolumn{6}{|c|}{ Age of Marriage } \\
\hline$<20$ years & $48(62.3 \%)$ & $29(37.7 \%)$ & 77 & \multirow{2}{*}{$x^{2}=3.052$} & \multirow[t]{2}{*}{0.09} \\
\hline$\geq 20$ years & $45(48.9 \%)$ & $47(51.1 \%)$ & 92 & & \\
\hline
\end{tabular}

Complete age during first pregnancy

\begin{tabular}{llllll}
\hline$<20$ & $30(66.66 \%)$ & $15(33.33 \%)$ & 45 & \multirow{2}{*}{$\chi^{2}=3.548$} & 0.170 \\
\cline { 1 - 3 } $20-26$ & $53(50 \%)$ & $53(50 \%)$ & 106 & & \\
\cline { 1 - 4 }$\geq 26$ & $10(55.6 \%)$ & $8(44.4 \%)$ & 18 & &
\end{tabular}

Total Live birth

\begin{tabular}{llllll} 
Primiparous & $54(55.1 \%)$ & $44(44.9 \%)$ & 98 & \multirow{2}{*}{$\chi^{2}=0.00$} & 1 \\
\cline { 1 - 4 } Multiparous & $39(54.9 \%)$ & $32(45.1 \%)$ & 71 & &
\end{tabular}

Labor time(Primiparous)

\begin{tabular}{llllll}
\hline$<14$ hours & $28(52.8 \%)$ & $25(47.2 \%)$ & 53 & $\chi^{2}=0.007$ & 1 \\
\cline { 1 - 4 }$\geq 14$ hours & $14(53.8 \%)$ & $12(46.2 \%)$ & 26 & &
\end{tabular}

Labor time(Multiparous)

\begin{tabular}{|c|c|c|c|c|}
\hline$<8$ hours & $20(52.6 \%)$ & $18(47.4 \%)$ & 38 & $x^{2}=0.021$ \\
\hline$\geq 8$ hours & $12(54.5 \%)$ & $10(45.5 \%)$ & 22 & \\
\hline
\end{tabular}

Table 5 shows the association between reproductive health related characteristics with women's satisfaction. None of the variables were found statistically significant.

\section{Association of Health Service related Characteristics with Women's Satisfaction during delivery period}

Table 6: Association of health services related characteristics with women's satisfaction. 
Variables Women's satisfaction

Total Chi-square p-value

Satisfaction Dissatisfaction

93(55\%) 76(45\%)

\section{Type of delivery}

$\begin{array}{llllll}\text { Normal } & 71(54.2 \%) & 60(45.8 \%) & 131 & \chi^{2}=0.163 & 0.715 \\ \text { Abnormal } & 22(57.9 \%) & 16(42.1 \%) & 38 & & \end{array}$

Health status of mother

$\begin{array}{lllll}\text { Normal } & 92(54.8 \%) & 76(45.2 \%) & 168\end{array} \chi^{2}=0.817 * \quad 1$

\section{Health status of child}

\begin{tabular}{llllll} 
Normal & $89(55.3 \%)$ & $72(44.7 \%)$ & 161 & \multirow{2}{*}{$\chi^{2}=0.085^{\star}$} & 1 \\
\cline { 1 - 3 } Abnormal & $4(50 \%)$ & $4(50 \%)$ & 8 & &
\end{tabular}

Duration of stay in hospital(Days)

$\begin{array}{llllll}<2 \text { days } & 60(56.6 \%) & 46(42.4 \%) & 106 & \chi^{2}=0.285 & 0.633 \\ 22 \text { days } & 33(52.4 \%) & 30(47.6 \%) & 63 & & \end{array}$

\section{Cost of health services}

$\begin{array}{llll}<13000 & 48(62.3 \%) & 29(37.7 \%) & 77\end{array} \chi^{2}=2.888 \quad 0.105$

\section{Distance of health facilities}

\begin{tabular}{llllll}
\hline$<1$ hour & $63(55.8 \%)$ & $50(44.2 \%)$ & 113 & \multirow{2}{*}{$\chi^{2}=0.072$} & 0.87 \\
\cline { 1 - 4 }$\geq 1$ hour & $30(53.6 \%)$ & $26(46.4 \%)$ & 56 & &
\end{tabular}

\section{Receive incentive}

\begin{tabular}{llllll}
\cline { 1 - 3 } Yes & $86(56.6 \%)$ & $66(43.4 \%)$ & 152 & \multirow{2}{*}{$\chi^{2}=1.466$} & 0.305 \\
\cline { 1 - 3 } No & $7(41.2 \%)$ & $10(58.8 \%)$ & 17 & &
\end{tabular}

\section{*Fisher exact test}

Table 6 expresses association between health service related characteristics with women's satisfaction. None of the variables were found statistically significant.

\section{Discussion}




\section{Satisfaction on Institution Delivery Services}

According to survey (55\%) of the participant were satisfied with institutional delivery services provided by public health centers. The level of satisfaction was $56 \%$ in Sri-Lanka, $51.9 \%$ in South Africa and $54.5 \%$ Kenya which were said to be similar studies of this research. In the similar case, the studies conducted in South Australia and Bangladesh, $86.1 \%$ and $92.3 \%$ women were satisfied respectively. ${ }^{[24]} \mathrm{A}$ study in Ethiopia states that $90.26 \%$ women were satisfied with institution delivery services. Similarly some other studies on Ethiopia state that $82.9 \%$ and $61.9 \%$ women were satisfied. ${ }^{[7]} \mathrm{A}$ study conducted in Nepal states that the overall satisfaction on institution delivery services was $45.1 \%$ while it was $58.1 \%$ in Kaski District. ${ }^{[25]}$ According to STS Survey in 2012 the level of satisfaction among Nepalese women was $90 \%$. But STS survey stated $86 \%$ satisfaction on their survey in 2013. ${ }^{[5]}$ The difference in level of satisfaction in other studies and ours could be because of study setting difference, more availability of health service facilities in different countries and could also because of methodological difference in which researcher used factor analysis to set the cutoff point for satisfaction.

Satisfaction was seen to be strongly correlated with the politeness and experience of staff as well as the health facilities that they received. A study in Nepal showed that clients were satisfied with care received at the facility $(86 \%)$, provider's skills $(85 \%)$, politeness of staff $(83 \%)$, waiting time $(80 \%)$, involvement in decision making (77\%), cleanliness (70\%), information received (69\%), and assured confidentiality (67\%). [22] The proportion of mothers who were satisfied with delivery care was nearly four-fifth $(79,1 \%)$. satisfaction levels for cleanliness was (35\%), presence of relatives or family to support women during child birth was (65.3\%) the client and emotional support during child birth. ${ }^{[26]}$ A study revealed that support for institutional delivery by mother-in-law and husband is associated with institutional delivery. ${ }^{[27]}$ Another study states that that two-third of the clients were satisfied or very satisfied with privacy in the facilities. ${ }^{[22]}$ Women who were treated with respect, courtesy and dignity and had trusting relationship with their care providers were more likely to be satisfied. ${ }^{[5]}$

\section{Socio-demographic variables with Satisfaction}

In this study, religion is considered as one of the variables associated with satisfaction in delivery services. But in other studies there was association between age group and education with overall satisfaction which was statistically significant. ${ }^{[28]}$ This study states that women who were 25 years and above, were more satisfied but the case was not found same to women whose age ranging from 20 to 34 years. This is to say, they were less satisfied with the care they received compared to women whose age from 35 to 49 years. ${ }^{[29]}$ A study in Chitwan shows Age ${ }^{[30]}$, parity and education were associated with the institution delivery services while this study didn't show any association. ${ }^{[31]}$ The difference in sociodemographic characters of the participants in other studies and our studies could be due to the variation in geographical status, standard of living, level of education, religion and status of family.

\section{Reproductive health variables with satisfaction.}


A study in Nepal states that one-third of Nepali women get married before 16 while $57 \%$ become pregnant at their adolescent but this study expresses that around two-third women get married after age twenty and more than seventh-tenth planned first baby after 20 years. ${ }^{[32]}$ With changing time period, increase in health education, restriction by government law and provision of education to girls could be reason for delay marriage which can further increases in decision making ability of female which ultimately reduces the pregnancy before the age of 20 years. A study conducted in public health facilities of Kenya states that more than half (51.7\%) were multiparous where as in this study $35 \%$ were multiparous. A tri-nation study states that decision regarding utilization of birthing facilities is often made by the husband or his family members rather than by the parturient woman ${ }^{[13]}$ where as another study of eastern Nepal showed that slightly more than half of the of decision for delivery point were made by mother and her spouse which is also considered as supporting details to this study. ${ }^{[33]}$ The reason behind this could be because of the patriarchal nature of society, where the final decision are mostly made by the husbands or elder persons of the household regarding delivery point. A study conducted in eastern Nepal showed that almost all (92.5\%) pregnancies were planned which supports our study. ${ }^{[33]}$ Increase level of education of our participants (female) and theirs husbands might be one of the reason for high planned pregnancy.

\section{Health services related variable with satisfaction}

Generally, more than eight-tenth (82.9\%) participants travelled for an hour according to the study conducted in Ethiopia while in this study around seventh-tenth (66.9\%) had travelled less than an hour to reach to health institution. ${ }^{[26]}$ This could be because of the topographical variation, transportation facilities, social beliefs and practices on delivering on urban health facilities rather than rural health facilities. A study in Pakistan states that public sector hospitals were more efficient in providing assurance to women which was consistent to our study. ${ }^{[34]}$ This could be because the Nepal government is increasing number of birthing center and provide free delivery service with travelling cost. So, believe towards the government health centers is increasing day by day. Discipline of staff, cleanliness and regular visits of doctors is found in public sector hospital which increased the satisfaction of women which is similar to our study ${ }^{[34]}$ The reason behind this could be due to the commitment of health staffs during the recruitment to provide quality services and also could be due to the individual nature of health service providers. A study in Northern Ethiopia states that having plan to deliver at health institution and laboring time of less than six hours were significantly and positively associated with maternal satisfaction on delivery service but there was no any association seen in our study among characteristics ${ }^{[23]}$. Only $40 \%$ of mothers were satisfied with the quality of the services as a study conducted in Nairobi ${ }^{[4]}$. A study states that women who received advice from health workers on danger signs for mothers had higher satisfaction which was similar to our study. This can be supported by practice in Nepal that, Female Community Health Volunteer (FCHV) are regularly involved in ground level to ensure the safety for the pregnant women. They promote safe motherhood, child health and other community based health issues and service delivery and also refer serious cases to health institution and motivate local people on healthy behavior. Women who had an opportunity to ask questions related to reproductive health to the health providers had higher satisfaction which shows consistency in our study. 
[5] This could be because of the provision of four ANC checkup for pregnant women in which they can ask maternal health related issues in four visit in health institution. Female staff like ANM and SBA are recruited in health institution so that every female can share their problem without hesitation. Another study states that incentives is not only for the utilization of institutional delivery services. It also states that incentives scheme increased the awareness in the community. ${ }^{[35]}$

\section{Conclusion}

According to the overall study majority of delivery service users were satisfied with institutional delivery services provided by public health facilities (centers). The level of satisfaction was seen higher in services for mother delivering in health centers and lower in availability of well managed visitor's bed in health facilities. Women using delivery services were more satisfied with infrastructure and health services. Majority of the participant were satisfied with time provided by health worker, their response towards the participant, co-operation during delivery period along with politeness of health staff. Respondents were dissatisfied with cleanliness of toilets, labor room, and availability of well managed visitor bed as well as with food services at hospitals. The study shows that religion was significantly associated with women's satisfaction where as other socio-demographic factors were not associated with women's satisfaction towards delivery services at public health facilities. Similarly, reproductive health characteristics and health services characteristics were not associated with women's satisfaction.

Quality of service is directly associated with environment around the health institution so hygienic environment should be maintained to ensure clean and safe delivery services that will ultimately increase the satisfaction of clients. Satisfaction with services is also associated with how visitors are managed in health institution so based on the findings of this study it is recommended that adequate number of visitor's bed along with their maintenance should be considered as an important factor in every health institution. Promoting free and quality delivery services through public health facilities is today's concern. So concerned authorities are recommended for considering need of people in community and are requested to address those with new service delivery equipment's and infrastructure which may further increase their satisfaction towards services and institution.

\section{Abbreviations}

ANC

Antenatal Care

ANM

Auxiliary Nurse Midwifery

CEONC

Comprehensive Emergency Obstructive and Neonatal Care $\mathrm{FCHV}$

Female Community Health Volunteer

IQR 
Inter-quartile Range

SBA

Skilled Birth Attendance

SDG

Sustainable Development Goal

STS

Service Tracking Survey

\section{Declarations}

\section{Ethical Approval and Consent to Participant}

Ethical approval was provided by Institute Review Committee of Pokhara University Research Centre. All the participant are informed about study. Participant were asked for the willingness to participate in the study. Participates signature was taken after the completion of data. Information were provided to participant who were willingness to know more about topic.

Consent for publication:

Non Applicable

Availability Of data and materials:

Data are analyzed in SPSS version 20 and can be provided by corresponding author after adhering to CISM policy on data sharing

Competing Interests:

No any competing interest

\section{Funding:}

Self-funded by the researcher.

\section{Authors Contribution:}

Literature search and review: ARP \& DKY

\section{Acknowledgement:}


I would like to express my sincere gratitude to all of those who provided their valuable assistance to accomplish this task successfully. I am grateful to the participants for graciously answering the question. I would like to extend my immense gratefulness to my friend Binayak Banstola, Dijson Dhakal, Basna Kumari Khatri and Rabina Poudel for their support, guidance, good co-operation and encouragement during my dissertation. I would also like to thank Mr. Upendra Ghimire for his guidance and support during the preparation of the article. Most importantly, my sincere gratitude goes to all the participants who directly and indirectly participate in the research study. So, I would like to cheer for all supporting hearts during the research project.

\section{References}

1. Cambridge Dictionary. Satisfaction [2018/07/15]. Available from: https://dictionary.cambridge.org/dictionary/english/satisfaction.

2. Bitew K, Ayichiluhm M, Yimam K. Maternal Satisfaction on Delivery Service and Its Associated Factors among Mothers Who Gave Birth in Public Health Facilities of Debre Markos Town, Northwest Ethiopia. BioMed research international. 2015;2015:460767.

3. Creanga AA, Gullo S, Kuhlmann AKS, Msiska TW, Galavotti C. Is quality of care a key predictor of perinatal health care utilization and patient satisfaction in Malawi? BMC Pregnancy Childbirth. 2017;17(1):150.

4. Bazant ES, Koenig MA. Women's satisfaction with delivery care in Nairobi's informal settlements. International journal for quality in health care: journal of the International Society for Quality in Health Care. 2009;21(2):79-86.

5. Mehata S, Paudel YR, Dariang M, Aryal KK, Paudel S, Mehta R, et al. Factors determining satisfaction among facility-based maternity clients in Nepal. BMC Pregnancy Childbirth. 2017;17(1):319.

6. Karkee R, Lee AH, Pokharel PK. Women's perception of quality of maternity services: a longitudinal survey in Nepal. BMC Pregnancy Childbirth. 2014;14:45.

7. Dewana Z, Fikadu T, Mariam GA, Abdulahi M. Client perspective assessment of women's satisfaction towards labour and delivery care service in public health facilities at Arba Minch town and the surrounding district, Gamo Gofa zone, south Ethiopia. Reproductive health. 2016;13:11.

8. Choulagai B, Onta S, Shrestha B, Subedi N, Bhandari G, Krettek A. Perceptions of users and providers on barriers to utilizing skilled birth care in mid- and far-western Nepal: A qualitative study2014.

9. Onta S, Choulagai B, Shrestha B, Subedi N, Bhandari GP, Krettek A. Perceptions of users and providers on barriers to utilizing skilled birth care in mid- and far-western Nepal: a qualitative study. Global Health Action. 2014;7(1):24580.

10. Pradhan P, Bhattarai S, Paudel I, Gaurav K, Pokharel P. Factors Contributing to Antenatal Care and Delivery Practices in Village Development Committees of llam District, Nepal2014. 60 - 5 p.

11. Riaz A, Zaidi S, Khowaja AR. Perceived barriers to utilizing maternal and neonatal health services in contracted-out versus government-managed health facilities in the rural districts of Pakistan. 
International journal of health policy management. 2015;4(5):279-84.

12. Exavery A, Kante AM, Njozi M, Tani K, Doctor HV, Hingora A, et al. Access to institutional delivery care and reasons for home delivery in three districts of Tanzania. Int J Equity Health. 2014;13:48.

13. Colombara DV, Hernandez B, Schaefer A, Zyznieuski N, Bryant MF, Desai SS, et al. Institutional Delivery and Satisfaction among Indigenous and Poor Women in Guatemala, Mexico, and Panama. PloS one. 2016;11(4):e0154388.

14. Gebrehiwot T, San Sebastian M, Edin K, Goicolea I. Health workers' perceptions of facilitators of and barriers to institutional delivery in Tigray, Northern Ethiopia. BMC Pregnancy Childbirth. 2014;14:137.

15. Hernandez B, Colombara DV, Gagnier MC, Desai SS, Haakenstad A, Johanns C, et al. Barriers and facilitators for institutional delivery among poor Mesoamerican women: a cross-sectional study. Health policy planning. 2017;32(6):769-80.

16. Higgins-Steele A, Burke J, Foshanji Al, Farewar F, Naziri M, Seddiqi S, et al. Barriers associated with care-seeking for institutional delivery among rural women in three provinces in Afghanistan. BMC Pregnancy Childbirth. 2018;18(1):246.

17. WHO. World health statistics 2018: monitoring health for the SDGs, sustainable development goals. 2018 2018/07/15. Report No.

18. Bhandari T. Maternal Child Health Situation in South East Asia2012.

19. Department of Health Services. Annual Report 2073/74. 2074.

20. Aldana JM, Piechulek $\mathrm{H}, \mathrm{Al}-\mathrm{Sabir}$ A. Client satisfaction and quality of health care in rural Bangladesh. Bull World Health Organ. 2001;79.

21. Chemir F, Alemseged F, Workneh D. Satisfaction with focused antenatal care service and associated factors among pregnant women attending focused antenatal care at health centers in Jimma town, Jimma zone, South West Ethiopia; a facility based cross-sectional study triangulated with qualitative study. BMC Res Notes. 2014;7:164.

22. 22.

23. Bitew K, Ayichiluhm M, Yimam K. Maternal Satisfaction on Delivery Service and Its Associated Factors among Mothers Who Gave Birth in Public Health Facilities of Debre Markos Town, Northwest Ethiopia. BioMed research international. 2015;2015:6.

24. Gitobu CM, Gichangi PB, Mwanda WO. Satisfaction with Delivery Services Offered under the Free Maternal Healthcare Policy in Kenyan Public Health Facilities. Journal of environmental public health. 2018;2018:4902864.

25. Neupane S. Client Satisfaction on Intranatal And Postnatal Services of Hospitals in PokharaLekhnath: Pokhara University; 2017.

26. Tesfaye R, Worku A, Godana W, Lindtjorn B. Client Satisfaction with Delivery Care Service and Associated Factors in the Public Health Facilities of Gamo Gofa Zone, Southwest Ethiopia: In a Resource Limited Setting. Obstetrics gynecology international. 2016;2016:5798068. 
27. Speizer IS, Story WT, Singh K. Factors associated with institutional delivery in Ghana: the role of decision-making autonomy and community norms. BMC Pregnancy Childbirth. 2014;14:398.

28. Sayed W, Abd El Aal DE, Mohammed S, Abbas H, Zahran A. K. Maternal satisfaction with delivery services at tertiary university hospital in upper Egypt, is it actually satisfying?2018. 2547 p.

29. Mekonnen ME, Yalew WA, Anteneh ZA. Women's satisfaction with childbirth care in Felege Hiwot Referral Hospital, Bahir Dar city, Northwest Ethiopia, 2014: cross sectional study. BMC Res Notes. 2015;8:528.

30. Maru S, Rajeev S, Pokhrel R, Poudyal A, Mehta P, Bista D, et al. Determinants of institutional birth among women in rural Nepal: a mixed-methods cross-sectional study. BMC Pregnancy Childbirth. 2016;16(1):252.

31. Shah R, Rehfuess EA, Maskey MK, Fischer R, Bhandari PB, Delius M. Factors affecting institutional delivery in rural Chitwan district of Nepal: a community-based cross-sectional study. BMC Pregnancy Childbirth. 2015;15:27.

32. Khatri R, Prasad Dangi T, Gautam R, Narayan Shrestha K, Homer SE. C. Barriers to utilization of childbirth services of a rural birthing center in Nepal: A qualitative study2017.

33. Dhakal P, Shrestha M, Baral D, Pathak S. Factors Affecting the Place of Delivery among Mothers Residing in Jhorahat VDC, Morang, Nepal2018. 2-11 p.

34. Andaleeb SS. Service quality perceptions and patient satisfaction: a study of hospitals in a developing country. Soc Sci Med. 2001;52.

35. Baniya A, Chhetri D, Pokhrel B. Maternity Incentive Scheme on Safe Delivery Services in Rural Area of Kavre District. Journal of Chitwan Medical College. 2015;5(12):30-5.

\section{Supplementary Files}

This is a list of supplementary files associated with this preprint. Click to download.

- InformConsentandDatacollectiontool.docx 